\title{
A propósito de la categoría género: leer a Joan Scott
}

\author{
María Luisa Tarrés \\ Doctora en Sociología (Universidad de París) \\ Profesora investigadora en El Colegio de México \\ mtarres@colmex.mx
}

\begin{abstract}
Resumen La contribución de Joan Scott a la teoría de género hoy resulta imprescindible. Sus estudios sobre la historia del feminismo y el esfuerzo por articular la categoría de género partiendo de un escenario histórico determinado también por la presencia y participación de las mujeres alimentan los debates más actuales en torno a las relaciones e identidades vinculadas con el género. Por ello, tomo como pretexto la publicación en español de su libro Género e historia (México, 2008) con el fin de estimular la relectura de una obra cuyo impacto en la política feminista ha sido significativo. Hacer una relectura crítica de este modelo puede también contribuir a enriquecer los estudios que lo recuperan desde la perspectiva de género. Pese al notable desarrollo de la teoría de género, la perspectiva de Scott tiende a ser utilizada en forma descriptiva privilegiando el análisis de problemas donde la desigualdad de las relaciones de género resulta limitada y evidente. Sugiero entonces interpelar a Scott articulando el contexto de su obra y el de nuestro tiempo con el fin de extender el campo de análisis y la comprensión de las lógicas culturales e institucionales que influyen en la experiencia de las relaciones de género.
\end{abstract}

Palabras-clave: Joan Scott, teoría de género, relaciones de género.

T a contribución de Joan Scott a la teoría de género hoy resulta Limprescindible. Sus estudios sobre la historia del feminismo y el esfuerzo por articular la categoría de género partiendo de un escenario histórico determinado también por la presencia y participación de las mujeres alimentan los debates más actuales en torno a las relaciones e identidades vinculadas con el género. Por ello, tomo como pretexto la publicación en español de su libro Género e historia (México, 2008) con el fin de estimular la relectura de una obra cuyo impacto en la política feminista ha sido significativo, sobre todo gracias al artículo "El género: una categoría útil para el análisis histórico" (Scott, 1986), incluido en este volumen. ${ }^{1}$ Este es, probablemente, su trabajo más conocido debido a que su difusión coincidió con el momento en que las reivindicaciones del movimiento feminista lograron incidir en el campo político y en las instituciones a nivel nacional e internacional. Su influencia fue primordial ya que planteó una interpretación que logró unificar posturas aparentemente incompatibles en torno a las cuestiones de género. Así pues, el acercamiento a la obra de Scott sobre el contexto de la sociedad actual señala que la noción de género y las relaciones de género son un tema abierto, a pesar de que han transcurrido más de 25 años desde que la autora propusiera su modelo interpretativo.

1. Este artículo fue traducido anteriormente a varios idiomas, sin embargo, la obra Género e historia constituye un conjunto de trabajos que la autora examina con una mirada retrospectiva y una reflexión que enriquece su contenido para esta última versión en castellano. 
Hacer una relectura crítica de este modelo puede también contribuir a enriquecer los estudios que lo recuperan desde la perspectiva de género, cuyo punto de partida es el lugar subordinado que ocupan las mujeres en las sociedades contemporáneas. Asimismo puede ayudar a documentar la reflexión a partir de la cual parten los gobiernos para cimentar estrategias de cambio desde que se firmaron los Acuerdos de Beijing en 1995. Pese al notable desarrollo de la teoría de género, la perspectiva de Scott tiende a ser utilizada en forma descriptiva privilegiando el análisis de problemas donde la desigualdad de las relaciones de género resulta limitada y evidente. Releer a Scott permite profundizar en la reflexión teórica sobre esta perspectiva, más allá de sus indicadores empíricos.

Sugiero entonces interpelar a Scott articulando el contexto de su obra y el de nuestro tiempo con el fin de extender el campo de análisis y la comprensión de las lógicas culturales e institucionales que influyen en la experiencia de las relaciones de género. Leer no es un acto ingenuo que se limite a captar letras y palabras, la lectura es un proceso constructivo, una interacción entre pensamiento y lenguaje, es un acto social. Cada lector responde de forma diferente a un mismo texto, descubre y construye el sentido de las ideas a través de una selección, combinación u organización distinta, elaborando por tanto significados propios (Goodman, 1982). Y en esas lecturas se juega sin duda la cultura, el lugar social al que se pertenece y la experiencia subjetiva. Hay textos que responden a lectores socialmente homogéneos, logrando una enorme comunicación con la propuesta escrita, tal como sucede con quienes, como yo, leemos a una teórica feminista que nos otorga claves para interpretar los significados de los malestares y problemas derivados de la diferencia sexual que enfrentan los seres humanos, especialmente las mujeres y otras sexualidades discriminadas debido a su posición subordinada, impidiéndoles transformarse en sujetos reflexivos.

En este sentido, la obra de Scott se erige como una especie de caja de herramientas teórico-metodológicas que además de entrever el problema ofrece caminos lógicos para acceder a él y conocerlo. Su tardía traducción al castellano actúa entonces como telón de fondo de un diálogo entre la autora y sus lectores que sin proponérselo crean un nuevo texto, quizá varios, a la luz de la realidad social contemporánea donde la categoría de género produce aún acérrimas controversias.

Quisiera remarcar que la propuesta de Scott elaborada en 1986 y plasmada nuevamente en el libro del año 2008, se vincula directamente con el desarrollo del pensamiento y la militancia feminista pese a que en la actualidad las circunstancias socio-políticas han contribuido a sobre utilizarla y así neutralizar su postura crítica. Los equívocos derivados de este texto resultan de argumentos legitimadores y de políticas sociales conservadoras que esconden su contenido transformador.

En este marco, mi reflexión se aboca a ubicar el aporte de Scott centrado en el reconocimiento de la importancia de las mujeres en la historia y paralelamente a construir una perspectiva teórica que después de muchos años cristaliza en "la categoría de género". Aun cuando sabemos que la autora continúa trabajando intensamente sobre los vínculos de la elaboración cultural de la diferencia sexual con la vida social y política, mi lectura sobre su trabajo es selectiva. Discute algunos aspectos de su pensamiento que, a modo de muestra, proponen estimular una nueva lectura y discusión de sus textos con el fin de actualizar el debate y comprender su aporte como un esquema flexible que permita continuar el diálogo alrededor de las cuestiones de género.

En un primer momento, este trabajo parte de las circunstancias históricas e intelectuales que influyeron en la trayectoria de Scott. Luego se presenta brevemente el proceso de elaboración de la categoría de género, destacando que su claridad analítica obedece en gran medida a la pregunta por la desigualdad derivada de las diferencias entre los sexos. Se plantea también que el éxito de la difusión de la propuesta, inesperado para su autora, en el debate y la política internacional resultó de lecturas pragmáticas, ajenas a la intención del proyecto teórico.

A pesar de que el uso y abuso de esta noción ha sido generalizado, se valora su contribución al reconocimiento de la mujer en los ámbitos políticos e institucionales del mundo así como su aporte a los debates académicos posteriores a su publicación. En esta línea de reflexión, señalamos brevemente algunas críticas y reelaboraciones de la categoría de género derivadas principalmente de la perspectiva del feminismo postcolonial que ha tenido importancia en los países periféricos y de la perspectiva del feminismo postmoderno asentado sobre la argumentación filosófica y psicoanalítica de Judith Butler, que tomamos como referencia por la extensa difusión de sus ideas en la academia mexicana y latinoamericana.

Finalmente, se esboza una de las diversas posturas presentes en las ciencias sociales que ofrecen las herramientas teóricas y metodológicas para comprender a los sujetos sexuados en la historicidad de su tiempo. Mi reflexión se limita a señalar las respuestas indicadas por algunos autores que reconocen el papel del inconsciente en la formación de las identificaciones sexuales, así como los códigos culturales que se inscriben en los discursos de las identidades de género. De este modo es posible ubicar a los individuos como sujetos reflexivos que pese a estar condicionados por la lógica de las relaciones de poder, también las administran, incidiendo así en su reproducción o en la producción de códigos de relación alternativos. 


\section{Contexto y desarrollo intelectual de Joan Scott}

El aporte de Scott se ubica en la experiencia de una generación, concebida como un grupo de personas de edades semejantes, que comparten un proceso histórico y son portadoras de proyectos, creencias o pautas comunes que le otorgan unidad y afloran con vigor en determinadas coyunturas. A finales de los años sesenta del siglo XX, la generación de Scott vivió la crisis de las divisiones disciplinarias en las ciencias sociales producida por una fuerte crítica a las bases epistemológicas, teóricas y metodológicas que redefinió sus campos y objetos de estudio.

El desarrollo de esa crítica se asentó básicamente en dos procesos difícilmente separables. Por un lado, los países se vieron desgarrados por disturbios urbanos, procesos de descolonización y guerras, que derivan en manifestaciones generalizadas por la paz y la proliferación de movimientos estudiantiles en Francia, México, Estados Unidos, Japón y otros países. En Checoslovaquia, un país socialista, hubo intentos por humanizar el rostro del comunismo y en América Latina la revolución cubana estimuló movimientos democratizadores de gran impacto para la vida socio-política que posteriormente derivaron en dictaduras militares, conflictos armados y otras manifestaciones de carácter inconmensurable que costó mucho superar.

Por otro lado, los procesos de institucionalización de las ciencias sociales en universidades y centros de investigación, desde la Segunda Guerra Mundial tanto en Europa como en Estados Unidos, lograron una gran influencia en la academia mundial y paradójicamente contribuyeron a la formación de profesionales, intelectuales y académicos en los márgenes del mundo político y social, ${ }^{2}$ cuya experiencia histórica aparecía en una posición secundaria o subordinada en los discursos y representaciones provenientes de los dos centros de producción de conocimiento.

Hasta ese momento esos centros de producción intelectual, institucionalizados en disciplinas, teorías o investigaciones, elaboraron un cúmulo de conocimientos que excluyó, marginó e incluso legitimó la dominación sufrida por estos actores. La experiencia de "los otros y de los diferentes" se explicó desde una serie de supuestos, en principio universales, que legitimaron el dominio, la dependencia y el menosprecio de las ideas y propuestas generadas por estos actores periféricos. Ello duró hasta que "esos otros", siempre en interlocución con aquellos ubicados en el centro, lograron una cierta autonomía y forjaron otro discurso para nombrar, desde su lugar, esa experiencia que no encajaba ni en los argumentos ni en las prácticas de las disciplinas establecidas. Los intelectuales estudiaron cómo las palabras pueden encerrar distintos significados simultáneamente y desconfiaron cada vez más en que el lenguaje transmitiera un mensaje único.

Si bien la postura crítica ante el lenguaje se desarrolló durante todo el siglo XX, en los años sesenta y setenta no solo puso en tela de juicio los fundamentos del pensamiento occidental sino que se abocó al desarrollo de herramientas teórico-metodológicas para demostrarlo. Si bien hay distintas posturas ante el lenguaje, se pueden señalar grosso modo dos corrientes: la que plantea que el lenguaje apunta de algún modo hacia el mundo externo y la que afirma que el lenguaje no guarda una relación de representación, o por lo menos que dicha relación se realiza dentro de contextos autónomos de significado.

Es esta última la que tuvo mayor influencia en el feminismo si consideramos el papel de Jacques Derrida que introdujo el concepto de deconstrucción ${ }^{3}$ del lenguaje, muy utilizado en los estudios de género y la importancia de la noción de discurso vinculado a la sexualidad y al poder de Michel Foucault. Ambos filósofos, cuyas biografías transcurren en la periferia, ${ }^{4}$ criticaron el discurso de la filosofía y de las ciencias sociales revelando que se encontraba marcado por relaciones de poder, por lo cual invariablemente excluía, reprimía o marginaba a "los otros", a los diferentes, funcionando de tal manera que uno de los términos tenía primacía y marginaba al otro. Se crearon así las bases para una crítica sistemática del pensamiento moderno, que trataba de racionalizar hechos pasados desde lo contemporáneo para legitimar la razón y el poder de la modernidad misma, eludiendo el contexto histórico y las instituciones que lo reproducían, imponiendo ciertas ideas sobre lo verdadero y lo falso, lo bueno y lo malo, lo moral y lo inmoral, lo normal y lo patológico, lo masculino y lo femenino.

Sin duda, el desarrollo de estas posturas revolucionó también la vida académica latinoamericana que en los años setenta experimentó lo que el sociólogo José Nun (1981) llamó "la rebelión del coro" cuando se refirió a la incapacidad teórica de las ciencias sociales para comprender la aparición de movilizaciones y movimientos sociales de estudiantes, mujeres, po-

\footnotetext{
2. En este caso, excolonias y países periféricos, así como en el surgimiento de actores inesperados en el mundo público tales como homosexuales, negros, mujeres o indígenas.

3. Ver sus primeros escritos La estructura, el signo y el juego en el discurso de las ciencias humanas, La escritura y la diferencia, De la gramatología y La voz y el fenómeno. El autor publicó más de 20 libros y numerosos artículos que continúan desarrollando su pensamiento filosófico.

4. El primero por ser judío, nacido en Argelia durante la colonización francesa, y el segundo por su homosexualidad.
} 
bladores urbanos o indígenas que irrumpieron en el escenario sociopolítico, rompiendo con el guión de la obra planteado por las teorías vigentes pues el "coro" en la tragedia latinoamericana desplazó a los actores principales que definían ese guión.

La articulación entre los procesos sociales y las disciplinas dedicadas a su estudio son complejas, se constituye, sin embargo, en el contexto de relaciones donde se desenvuelven las biografías individuales así como sus proyectos académicos. Por eso, supongo, que es allí donde se moldea la trayectoria académica de Scott (Abelson, Abraham; Murphy, 1989) y la de otras feministas de esa generación cuyo interés intelectual se vinculó con un compromiso político derivado de experiencias similares.

En el caso de Joan Scott rescatamos un temprano compromiso político con la izquierda norteamericana, pues creció en un íntimo contacto con la militancia sindical. Sus padres, Lottie y Sam Wallach, fueron víctimas de la cacería de brujas del macartismo por participar en el sindicato de maestros de Nueva York. Scott creció así en un ambiente estructurado alrededor de la política que se constituyó en un estilo de vida, un modo de ubicarse y pensar el mundo. En una entrevista, reconoció que esa socialización creó en ella un estrecho vínculo con el conocimiento, la enseñanza y la voluntad de saber, al punto que al finalizar los estudios secundarios (high school) se formó como maestra, de acuerdo con la tradición laboral y política de su familia. Sin embargo cumplió a medias con ese mandato pues sus credenciales académicas le permitieron continuar los estudios de historia en la Universidad de Wisconsin-Madison donde tuvo un excelente desempeño y, según sus propias palabras, comprendió, quizá para su tranquilidad, "que la producción de conocimiento es también un proceso político”. Logró así unir los dos hilos que marcan su socialización temprana y que a la vez la acercan a aquellos de su generación que criticaron formas caducas de dominación social y política, y plantearon la necesidad de entender en otros términos la vida social.

La vida académica de Scott como historiadora comenzó en los años setenta cuando llevó a cabo estudios sobre la izquierda, el radicalismo, la Revolución francesa y continúa posteriormente con la historia social donde las obras de E.P. Thompson, Eric Hobsbawm y Charles Tilly tuvieron una gran influencia. El encuentro con la obra de Thompson fue decisivo ya que su libro La formación histórica de la clase obrera en Inglaterra (1963) permitió a Scott realizar una crítica que cuestionó su pretendido universalismo, marcando con esto el despegue de su carrera pues despertó la admiración de colegas y estudiantes, especialmente en Inglaterra.

Scott planteó que el historiador británico carecía de distancia respecto a la definición de clase obrera pues solo la definía en términos masculinos y omitía todo lo concerniente a las mujeres, las desaparecía pese a que en su perspectiva el autor enfatizaba la vida cotidiana y no solo la política del mundo obrero, a diferencia de lo que había hecho en sus trabajos anteriores. Thompson no solo omitió el papel de las trabajadoras y su participación como militantes sindicales sino también a las madres, esposas e hijas que aseguraban la reproducción de la vida cotidiana. Desde ese momento, Scott se propuso un programa de trabajo y de investigación orientado a visibilizar y reflexionar sobre la experiencia de las mujeres, incorporándose activamente como historiadora feminista al debate académico de su tiempo y generación.

De ahí se desprende una obra que se desarrolla y orienta a cuestionar la historia convencional, cuyo propósito es mostrar que la exclusión de las mujeres de la narración histórica no se soluciona agregándolas como una subárea o especialidad de la disciplina, pues su sola presencia y visualización pone en jaque la idea de "hombre universal" que confunde lo humano con lo masculino y se filtra tanto en el lenguaje de la investigación como en el relato histórico.

Por lo tanto, Scott cuestiona las bases epistemológicas de esa forma de reflexionar y plantea la necesidad de una nueva historia que incluya a los seres humanos con todo y sus identidades sexuales. En esta tarea Scott orientó su trabajo por dos caminos paralelos, el político, desarrollado en las universidades para abrir espacios a las mujeres en posiciones de equidad y el académico donde aún despliega una trayectoria orientada a la creación de su propuesta disciplinaria.

Pese a sus objetivos centrados en la historia, esa obra sistemática se constituyó en una herramienta de análisis para las ciencias sociales, las humanidades y el psicoanálisis. Y es que el artículo "El género: una categoría útil para el análisis histórico”, que se ha leído en forma aislada, fue el resultado de un largo trabajo de reflexión e investigación. No se trató de un producto de la genialidad o de la casualidad sino de un debate sobre el género que comenzó en los años setenta y en el que participaron académicas feministas desde distintas disciplinas en todo el mundo. Fue la capacidad teórica, el cuidado metodológico, el estudio sistemático y crítico de esas propuestas lo que permitió a Scott elaborar esta perspectiva analítica.

Su propósito fue "repensar los determinantes" de las relaciones de género y para justificar su enfoque planteó que "ya no se trata de la historia de lo que ocurrió a las mujeres y los hombres y la manera en cómo ellos y ellas reaccionaron; se trata más bien de la significación subjetiva y colectiva que una sociedad da a lo masculino y lo femenino y cómo al hacerlo, ella confiere a las mujeres y a los hombres sus respectivas identidades" (Scott, 1999, p. 6). Desde mi punto de vista, la contribución de Scott consistió en 
sistematizar las aproximaciones al tema realizadas con anterioridad y elaborar una lógica analítica realmente útil para teorizar sobre la categoría de género, ${ }^{5}$ rompiendo la ambivalencia entre una perspectiva cultural y otra materialista, que había marcado la reflexión sobre el sistema sexo-género hasta entonces.

Scott destacó que la categoría de género es un elemento constitutivo de las relaciones sociales basadas en las diferencias percibidas entre los sexos y es una forma primaria de relaciones significantes de poder. Dicho de otro modo, las relaciones entre hombres y mujeres basadas en una jerarquía de poder provienen de representaciones simbólicas sobre la diferencia sexual y operan desde los procesos sociales más elementales. En consecuencia, "los cambios en la organización de las relaciones sociales corresponden siempre a cambios en las representaciones del poder" (Scott, 1986). Uno de los logros en esta construcción fue situar la categoría de género en el nivel simbólico-cultural y definirla desde ahí a partir de relaciones de poder cuyo cambio o reproducción está sujeto a factores vinculados con la historicidad de las instituciones y la organización social de los espacios donde se desarrolla la experiencia de los individuos.

Así Scott logra salir de la compleja búsqueda anterior al dejar de preguntarse por qué las mujeres constituyen un sector subordinado, independientemente del tiempo histórico y del espacio social en que transcurren sus vidas. En lugar de ello, se pregunta cómo funciona la lógica de las relaciones de género y la consecuente subordinación de la mujer. No es un cambio banal en la pregunta. Jacques Monod, un destacado biólogo y filósofo de la ciencia, señaló en 1970 que la biología como disciplina logró el gran desarrollo que tuvo hasta hoy cuando dejó de preguntarse por el origen o el por qué de la vida y comenzó a preocuparse por el cómo funciona la vida. La pregunta de Scott es similar y nos ubica en un problema que, aunque no está resuelto, ofrece la posibilidad de conocerlo y revelar sus mecanismos.

Hay que reconocer que la obra de Scott releva un problema poco analizado en las disciplinas sociales cuando se refiere al lenguaje, que juega un papel central en el uso de teorías críticas. La autora las utiliza como postura metodológica para deconstruir los archivos y la documentación histórica, como medio de alerta ante las narraciones científicas, cuestión que debemos considerar cuando se trata de descubrir el sexismo que se filtra en el conocimiento heredado. ${ }^{6}$ $\mathrm{Y}$ en efecto, la deconstrucción del discurso convencional tal como se dijo antes, permitió romper dicotomías, incluir la diferencia, reconocer las jerarquías, las exclusiones e inclusiones y por tanto visibilizar el orden de género presente en fuentes de datos, metodologías y teorías.

Es en este marco que la categoría de género como dispositivo analítico logró ser integrado en las ciencias sociales, más allá del propósito de su autora, que lo trabajó a partir de la historia y con el fin de redefinirla como disciplina. Así la sociología, la antropología, la psicología o el psicoanálisis, la literatura, la filosofía y en general las humanidades, han aprovechado esta categoría para integrarla a las perspectivas teóricas y metodológicas de sus disciplinas cuyos fundamentos se han desestabilizado y sus fronteras se han abierto con los cambios señalados al comienzo de esta reflexión.

Como se puede observar, el aporte de Scott no se limitó a la constitución de la categoría de género. Sus textos son fuente de inspiración para el trabajo académico, rebasando de lejos la disciplina de la historia, lo cual ha significado un notable desarrollo del cuerpo analítico en torno al género que propició enfoques interdisciplinarios y la articulación de diversos campos de conocimiento.

\section{La propuesta de Scott y otras posturas en torno a las identidades de género}

Pese a que las nociones de identidad e identidades de género, ocupan hoy día un lugar central en las ciencias sociales, su definición es muchas veces incierta debido a que abre debates de gran interés al remitir a diversas teorías y contextos sociales que la alejan de una visión única. El feminismo académico ha dedicado muchos esfuerzos al análisis de las identidades de género y esta centralidad genera posturas sobre las que no hay consenso.

Las ciencias sociales tienen una larga tradición sobre el tema y lograron establecer mediaciones entre las identidades, las identificaciones muchas veces cambiantes, el mundo simbólico cultural, el institu-

\footnotetext{
5. Hay que recordar que Gayle Rubin (1975) fue la primera académica que intentó comprender la condición de subordinación universal de las mujeres al articular, en un modelo único, diversos niveles de análisis derivados de la teoría marxista, estructuralista y psicoanalítica. Sin embargo, su propuesta fundamentada en orígenes teóricos diversos, no logra la consistencia necesaria para constituirse en una herramienta analítica productiva.

6. Resulta útil recordar que fue Simone de Beauvoir (1949) quien inició este tipo de reflexiones. Esta autora demostró con una claridad y paciencia impresionantes las diversas formas en que el sexismo penetra el conocimiento de las diversas teorías y disciplinas (biología, psicoanálisis, historia, literatura y filosofía). Aunque su análisis se detiene en la Segunda Guerra Mundial, su postura y metodología se acercan a la realizada por la perspectiva de género contemporánea. (Véase en el primer volumen "Los hechos y los mitos" de El segundo sexo, 1989.)
} 
cional normativo y las prácticas sociales para analizarlas en el contexto de las sociedades históricas. Quizá por ello la apropiación del modelo de Scott ha sido más sencilla en estas disciplinas, aunque por ello mismo también ha generado intensos intercambios tanto entre las académicas del tercer mundo como entre las que apuestan al pensamiento postmoderno que descentra las identidades.

Las primeras critican la noción de identidad de género hegemónica por su etnocentrismo, pues generaliza la experiencia de las sociedades occidentales que, al dicotomizar la diferencia sexual, no logra conceptualizar las diferencias contenidas en la simbolización y la práctica de las relaciones de género en el resto de las sociedades. En estas críticas también se plantea que Scott simplifica las identidades al excluir la dominación de clase, etnia o la experiencia de dominación colonial y de dependencia que en muchas sociedades marcan la identidad y sexualidad de los sujetos. La identidad, para estas académicas, no estaría influenciada exclusivamente por las relaciones de poder entre los géneros sino también por las que se establecen en el discurso y los espacios político, étnico o de clase, presentes no solo en el sur sino también entre los grupos sociales subordinados que integran las sociedades del norte.

Por su lado, las académicas dedicadas a la identidad sexual inspiradas en el pensamiento postmoderno rechazan apasionadamente la visión dicotómica que proyecta el modelo de Scott. Aducen que este sustituye la palabra sexo femenino y masculino por género masculino y femenino sin proponer una perspectiva más amplia que incluya las diferentes formas en que se expresan las identidades sexuales. Aunque los argumentos de las postmodernas son más complejos, vale la pena resaltar que se basan en un rechazo del feminismo hegemónico utilizando sus mismas herramientas críticas. Afirman que esta versión del feminismo es víctima de la influencia del pensamiento universalista que dicotomiza las identidades sexuales, desdibujando las diferencias y matices que adquieren en la práctica social.

El razonamiento de Scott sobre las identidades de género ha sido en muchos sentidos la fuente de la que surgen estas interpretaciones disímiles e incluso opuestas. $^{7}$ Su trabajo funciona entonces como detonante y desencadena interpretaciones que han abierto caminos a otras modalidades para desarrollar la teoría y la investigación sobre identidades y relaciones de género. Por ello es importante recordar brevemente el acercamiento de esta autora fundacional a las iden- tidades de género, enfatizando que se aproxima a su estudio a través de un diálogo con el psicoanálisis y gracias a una valoración del lenguaje y del discurso, que funcionan a la vez como dispositivo de disciplinamiento y creatividad.

Scott, lectora de las diversas corrientes psicoanalíticas, detecta la imposibilidad de hacer equiparables la estructura subjetiva individual con las características del género como construcción simbólica cultural de modo que lo masculino y lo femenino coexisten o se superponen en la instancia inconsciente del psiquismo. Así, el psicoanálisis muestra la disposición bisexual de los individuos, gracias a la cual las relaciones edípicas se ordenan en un sistema de identificaciones que definen las opciones sexuales. De este modo, el objeto del deseo no está afuera sino se crea en un proceso interior, en el inconsciente de cada individuo y depende de factores vinculados con las formas de resolución del drama edípico.

La sexualidad es parte constitutiva de los seres humanos. Sin embargo, estos no poseen una identidad sexual anterior al desarrollo del complejo edípico que los oriente a identificarse con un objeto masculino o femenino. Esa resolución es siempre incompleta. Scott toma como punto de partida este axioma psicoanalítico en tanto le permite establecer que en la vida cotidiana la identificación y la opción sexual adquiere modalidades flexibles, pese a la presencia de prescripciones culturales rígidas que tienden a dicotomizar las categorías femeninas y masculinas. Es en este sentido que hay que leer el modelo analítico de Scott cuando refiere al género masculino y femenino ya que detrás de esas categorías culturales hegemónicas existe todo un razonamiento que se apoya en una lectura cuidadosa del psicoanálisis que, como hemos visto, reconoce la pluralidad de opciones sexuales. Debido a ello, es difícil criticar a Scott por dicotomizar las identidades de género, pues su modelo distingue el nivel subjetivo individual donde estas son ambiguas por el modelo cultural que los reduce a una norma: lo femenino y lo masculino.

Más aún, ello fortalece esa distinción si consideramos que la autora también apuesta al lenguaje y al discurso como el lugar para analizar al sujeto. La reflexión de Michel Foucault le permite pensar la historia como un modo de conocimiento y a la vez acercarse al trabajo empírico, lo que significa considerar que el "discurso refiere por un lado a las relaciones entre el conocimiento y el poder y por otro a la forma en que las personas adquieren existencia social cuando se transforman en objeto de conocimiento"

\footnotetext{
7. Más aún, si se ahonda en ellas se descubre que el cuestionamiento se asienta en general en una lógica que se nutre de las mismas teorías (por ejemplo, Foucault) y de deconstrucción como metodología. La diferencia con Scott se evidencia cuando se aplica en otros contextos nacionales o locales (la India, los países musulmanes o México), a sujetos cuyas identidades sexuales se encuentran excluidas (homosexuales, transexuales, bisexuales etc.).
} 
(Scott, 2009, p. 47). Los sujetos existen cuando son nombrados y ese nombre lo otorga un discurso que los ubica en jerarquías, los incluye o los excluye y explica cómo la diferencia sexual es transformada en desigualdad y subordinación social, pero también cómo en la vida social los seres humanos sexuados adquieren capacidad de agencia para trastocar las relaciones de poder. Con ello Scott supera la idea de sociedad como un teatro donde los actores juegan roles sexuales estereotipados o hiper-socializados ya que es en el lenguaje donde se expresa socialmente la singularidad y el deseo individuales. El lenguaje se constituye así en un objeto de estudio que permite introducir lo singular en la definición de las identidades sexuales, a la vez que las relaciones de poder legitimadas por los discursos institucionalizados son un camino para comprender cómo es que la diferencia sexual se transforma en desigualdad social.

Las bases teóricas de este modelo analítico remiten a lo que De Gaulejac (2002) denomina "lo irreductible psíquico", cuando refiere a las bases inconscientes de la psicología de las identidades individuales y argumenta que se trata de un nivel difícilmente asible no solo para hacer historia, como lo plantea Scott, sino también para la sociología y ciencias sociales en general. El supuesto es que lo propiamente individual, cuando se estudia lo social, se plasma a través de las maneras de ser socialmente definidas, se expresa en relaciones y prácticas sociales, en proyectos y en las historias de vida de los sujetos marcadas por sus contextos. La sociología, como otras ciencias sociales, incluye en consecuencia no sólo el lenguaje como lugar de observación y análisis sino también la experiencia individual y colectiva, lo que permite analizar al sujeto sin caer en un psicologismo que no maneja, recuperando así la subjetividad individual que se vincula con los objetos sociales y el orden simbólico-cultural donde este actúa. Esta forma de ubicar las identidades se hace posible en disciplinas que estudian a los individuos en relaciones sociales marcadas por estructuras de poder, atendiendo a sus palabras y observando sus prácticas en las sociedades contemporáneas. Con ello se evita dar por supuestas o adjudicar de antemano las identidades sociales donde se juega la identidad de género.

Observar las prácticas y escuchar las palabras en el espacio de relaciones sociales permite recuperar los significados y la subjetividad individuales. Aunque es probable que ello sea más difícil cuando se hace historia porque normalmente no se tiene un acceso directo a la palabra de los sujetos, es claro que la sociología y la antropología presentan la ventaja de contar con herramientas para estudiarlos en sus experiencias de interacción en distintos ámbitos y niveles de la vida social. Ello ha significado esfuerzos sostenidos para elaborar puentes entre los niveles micro y macro sociales, los comportamientos individuales, los procesos de interacción, la estructura social y el universo cultural, de modo que las teorías de primer grado cuentan con los recursos analíticos para trasladar la propuesta de Scott sin violentarla. Por el contrario, su adopción incluso cuando ha sufrido cambios por lecturas diferentes de lo social es relativamente suave. ${ }^{8}$

En este sentido, Scott ha contribuido a poner la atención en el lenguaje del conocimiento contemporáneo, elaborar una explicación sobre la exclusión femenina y la desigualdad entre los sexos basada en una mirada alternativa que enfatiza el ámbito simbólico para explicar cómo las diferencias biológicas se transmutan en construcciones culturales que marcan a la sociedad en su conjunto. Con base en una lectura distinta a la que prevaleció desde el siglo XVIII en adelante, Scott cambia la forma de concebir esa condición que discrimina a las personas cuya identidad de género no coincide con la del hombre universal que prevaleció hasta mediados del siglo XX como discurso hegemónico.

\section{La categoría de género en el debate postcolonial y postmoderno}

La influencia de la categoría de género no se limitó a la academia. La legitimidad lograda por esta categoría en el feminismo internacional, que por primera vez consigue incidir en reuniones como la Conferencia Mundial sobre las Mujeres celebrada en Beijing en 1995, es central para comprender el cambio radical del contexto en el que se debatió el tema. Su influencia traspasó el campo limitado donde actuaron las mujeres hasta ese momento cuando las distintas agencias de Naciones Unidas y de financiamiento internacional plantearon a los países miembros como condición para recibir apoyo a sus políticas públicas, la integración de la mujer al desarrollo y la ciudadanía. Aunque moralmente justos, los acuerdos de Beijing firmados por los gobiernos participantes, crearon fuertes conflictos y debates en las sociedades nacionales, especialmente por la oposición de sectores conservadores que, apelando a argumentos meta-sociales, 
interfirieron en la institucionalización de las demandas vinculadas con las relaciones y las identidades de género. ${ }^{9} \mathrm{El}$ problema no es banal si se piensa que la inclusión de la categoría de género en las políticas de desarrollo desestabilizó el orden cultural que transforma la diferencia anatómica en desigualdad entre los sexos y amenaza al mundo simbólico de sectores e instituciones que definen a la mujer como guardiana y reproductora de la familia.

Esos conflictos y discrepancias se desarrollaron en el interior de casi todas las sociedades en el ámbito de la política donde se producen luchas que, de acuerdo con la correlación de fuerzas, contribuyen o no a mejorar la condición de las mujeres. Más allá de ello la categoría de género ha generado debates en el seno mismo del pensamiento feminista donde se plantean diversas posturas para precisar su contenido. La sexualidad, las identidades y las formas de hacer política son asuntos que derivaron en interesantes divergencias y reflexiones en este campo. Estos debates muestran que es preciso considerar a la teoría de género como una obra inacabada., se trata de un trabajo abierto, sujeto a una serie de controversias que es preciso conocer, especialmente cuando se hace investigación.

Para ingresar al debate contemporáneo en torno a la categoría de género, recuperaremos dos corrientes que toman como punto de partida el modelo analítico de Scott y han tenido una fuerte influencia en México, América Latina y diversos países periféricos. Se trata del feminismo postcolonial y el postmoderno representado por Judith Butler.

El feminismo postcolonial cuestiona el peso que adquiere el género en las identidades propuesto por el feminismo de Occidente y apela a una redefinición igualitaria de las alianzas dentro del feminismo internacional para que se incluya la diversidad y no se imponga un proyecto único. Su crítica señala que la propuesta desarrollada por las académicas occidentales excluye su experiencia identitaria, moldeada también por la pertenencia étnica o nacional subordinada y por tanto, la acusan de un colonialismo discursivo. Basadas en las teorías de la subalternidad, desarrollan una línea académica diferente para analizar las identidades y relaciones de género a partir de la experiencia en sus sociedades.

Desde de los años noventa, esta corriente cobra importancia en México cuando los sectores populares se apropian del feminismo y se instala como tendencia después de 1994 con la presentación de la Ley Revolucionaria de Mujeres por las indígenas zapatistas que se definieron como aliadas de los varones por ser parte de la misma comunidad étnica y a la vez cuestionaron las tradiciones familiares o comunitarias que las subordinaban como género. ${ }^{10}$ Mostraron con ello una identificación y un compromiso con los varones de su comunidad alrededor de un proyecto de liberación para oponerse a la dominación externa pero, al mismo tiempo, plantearon una solidaridad en torno a la identidad de género. Se trató de dos identificaciones que el feminismo occidental no consideraba y que para las zapatistas era central, pues no negociaron la separación de las dos identidades cuando se vieron presionadas por diversos actores locales y nacionales.

El feminismo postcolonial se nutre especialmente de la corriente de estudios de los subordinados con arraigo en la historia social inglesa y en las ciencias sociales de la India que, curiosamente, al confluir con la propuesta cultural de las feministas chicanas y negras en Estados Unidos logró difundirse con fuerza en el movimiento feminista y la academia asiática, latinoamericana y africana. El punto que las une es la exclusión de su experiencia en la teoría de género y en la investigación realizada desde la visión occidental del feminismo. Valoran el esfuerzo teórico y la potencia de este discurso pero plantean la necesidad de un diálogo sobre las relaciones de poder que se infiltran en el discurso feminista occidental con el fin de incluir la experiencia de los países del sur en igualdad de condiciones. Esbozan también la necesidad de descolonizar el feminismo y aceptar que colonizadores y colonizados tienen un destino entretejido con el proyecto colonizador y la construcción de la otredad. En ambos grupos hay un discurso que dificulta un diálogo entre iguales pues el colonizador genera conocimiento sobre las mujeres del sur donde aparecen victimizadas, alienadas, incapaces de ser sujetos de su propia vida.

Por otro lado, al oponerse a una dominación común, las feministas del sur reconocen su dificultad para construir identidades autónomas como género pues tienden a priorizar proyectos que invisibilizan sus diferencias y desigualdades internas. De este modo el feminismo postcolonial se constituye en una postura que, si bien valora los aportes del feminismo occidental, se redefine a partir de una crítica cultural que aplica la deconstrucción a la experiencia histórica, la cual contrasta con la deconstrucción abstracta realizada por las occidentales.

Uno de sus planteamientos básicos es que la categoría "mujer" no corresponde a ninguna esencia

9. Cuestión que Scott reconoce con lucidez en el prefacio a la edición revisada en inglés del libro Género e historia, 2008.

10. Quien ha trabajado desde la antropología esta corriente en el país es Rosalva Aída Hernández y un grupo de investigadoras en Antropología del CIESAS cuyo interés se ha plasmado en diversas publicaciones. Entre ellas vale la pena mencionar: Suárez Navaz Liliana y Rosalva Aída Hernández (eds). Descolonizando el feminismo: Teorías y prácticas desde los márgenes. México: Ediciones Cátedra, Instituto de la Mujer, 2008. También, la obra de Saurabh Dube, quien ha publicado Sujetos subalternos: capítulos de una historia antropológica. Mexico: El Colegio de México, 2001. 
unitaria y unificadora, pues la pregunta debe desplazarse a la forma en que los discursos construyen esa categoría y a cuándo esa diferencia es pertinente en la diversidad de relaciones sociales. No existe una identidad única y homogénea llamada mujer. El feminismo occidental sitúa la diferencia biológica como explicación de la subordinación sin considerar que todos los sujetos colonizados comparten esa naturalización y son construidos en representaciones homogéneas en las que se incluyen a grupos e individuos muy diferentes y desiguales. En este sentido, reduce la dominación presente en una sociedad dando a la dominación sexual mayor importancia, llegando a conclusiones apresuradas respecto a la subordinación de las mujeres, sin considerar los distintos tipos de estructuras y discursos de poder que las someten tales como la pobreza, el racismo, la exclusión etc. Desde el comienzo se considera a los hombres como dominantes y a las mujeres dominadas, utilizando una visión dicotómica del poder omitiendo que el mismo Foucault, retomado por las feministas occidentales para argumentar sobre las relaciones de género, incluye en su propuesta las estrategias de resistencia al poder en diversas situaciones de interacción y su influencia en la identidad de los sujetos que analiza a través de la experiencia histórica.

La academia feminista postcolonial resulta también una crítica a la concepción política de las feministas de Occidente en la medida en que estas últimas aceptan las reglas del juego político proporcionadas por democracias estables para resolver sus demandas, cuando en las regiones dependientes lo que está en juego es la lucha contra la dominación externa, nacional comunitaria o étnica. En este sentido, las identidades de las mujeres se desarrollan alrededor de pertenencias diversas tales como la nación, la clase social, la raza o el género, difíciles de integrar en las nociones occidentales de ciudadanía, cultura, opción sexual, propuestas por el análisis de género en sociedades cuya organización política no coincide con el modelo de democracia liberal o republicana asumido por el feminismo occidental. Más aun, en estos países, regiones y comunidades se identifica a los países organizados con sistemas democráticos como la causa de su dominación y dependencia. De ahí que el feminismo postcolonial rechace la propuesta occidental que, en un mismo paquete, envuelve una perspectiva teórica con un proyecto político. La antropóloga Iris M. Young (2000) quien dialogó estrechamente con sus colegas del sur, aclaró la postura de esta corriente que cuestionó la universalidad de la noción de género al escribir que "se trata de una llamada a la desnaturalización de los sujetos epistemológicos y políticos del feminismo, planteando voces múltiples basadas no en la libre elección, sino en posicionamientos y experiencias sociales".

Pese a este distanciamiento hay que reconocer que las feministas del sur han reelaborado algunos valores del feminismo occidental que adquieren otros significados cuando los aplican a su experiencia histórica. El valor de la equidad en las relaciones de género no adquiere connotaciones separatistas pues señalan que comparten con los varones la defensa de sus comunidades dominadas por poderes externos, normalmente occidentales.

Cuando las académicas postcoloniales apelan al reconocimiento de identidades culturales diversas evidencian una dimensión no considerada por el feminismo occidental que se centra en las identidades de género y ubica en un lugar secundario las pertenencias comunitarias, de clase, etnia e incluso aquellas vinculadas con las ideologías y religiones que hoy tienen un gran poder en la generación de identidades colectivas. Al resaltar la importancia de la vida material en la definición de las identidades de género cuestionan las limitaciones de la teoría de género occidental que prioriza la perspectiva cultural como factor estructurante central de la desigualdad en las relaciones de género. ${ }^{11}$

En suma, la corriente postcolonial constituye un llamado de atención que, al ubicarse en el campo feminista, invita a reflexionar sobre la diversidad de los intereses de las mujeres y a evitar la imposición de discursos que desde una mirada hegemónica las excluye o victimiza, definiéndolas como sujetos pasivos. Pese a su crítica, esta apunta a proyectos similares a los de las feministas de occidente ya que, por un lado, luchan por la autonomía desarrollando un pensamiento situado en su experiencia y por otro apelan a alianzas equitativas con otras feministas del mundo.

La segunda corriente vigente en el debate académico contemporáneo, formada por diversos autores de orientación postmoderna, entre los que sobresale la filósofa Judith Butler otorga un lugar importante a las nuevas identidades sexuales. La crítica radical de Butler a la noción de identidad utilizada por el movimiento feminista y de mujeres desde la Ilustración hasta nuestros días cuestiona la artificialidad de los estereotipos de género y explora las diversas formas de expresión de la sexualidad. Butler representa una postura fundamentalmente filosófica, cuyo ideal es borrar el género como construcción cultural en la definición de los sujetos, lo que en términos políticos significaría renunciar a la acción colectiva, cuestión que ha suscitado el rechazo de la academia y la militancia feminista.

11. Sería importante comparar la corriente postcolonial con el feminismo socialista que también otorga una importancia central a las condiciones estructurales derivadas de la vida material en la formación de los sujetos. 
El problema planteado por Butler es complejo, ya que por un lado, su argumentación pone en duda nociones y supuestos instituidos en el feminismo académico y, por otro, presenta dificultades para ser traducido al lenguaje de lo social o lo político. Su obra se basa en una lectura crítica inspirada en Simone de Beauvoir que se extiende a la categoría de género. También se apoya en el psicoanálisis de orientación lacaniana que, en términos esquemáticos, plantea que el lenguaje, el discurso y el habla son falocéntricos, de modo que cualquier individuo que pretenda ser sujeto será necesariamente varón. Asimismo piensa al cuerpo construido culturalmente, pues hay una imposibilidad de acceder a lo natural, con ello plantea que no es posible distinguir entre sexo y género. El discurso ha disciplinado milenariamente a los cuerpos, obligando a varones y mujeres a desear la reproducción y jugar papeles predefinidos. ${ }^{12}$

Inspirada en las ideas de Simone de Beauvoir que rechazan la identificación de lo femenino con la naturaleza, es decir con el cuerpo/sexo, Butler apuesta como ella a la construcción de la mujer como sujeto a partir de la apropiación de la representación social de la masculinidad, ya que esta le otorga el control de la cultura y el conocimiento, bases para su trascendencia. De este modo para Butler, el sujeto de Beauvoir es una representación conceptual que rechaza el esencialismo (femenino-masculino) y toda referencia a la anatomía de los cuerpos. ${ }^{13}$

Butler se deslinda así de la postura del feminismo contemporáneo que acepta y se inscribe en la distinción anatómica natural entre los sexos para construir la división cultural entre los géneros que según ella legitima, sin proponérselo, la idea de sexo natural y la canoniza al sustituir género masculino y femenino por hombre y mujer. Para mostrar que el feminismo ha sido víctima de sus propias categorías, Butler lleva a cabo una reconstrucción de la genealogía de los cuerpos similar a la que realiza Foucault cuando piensa en la productividad del poder que se desarrolla fuera de los discursos hegemónicos desestabilizando sus fundamentos.

Para resolver este problema, la autora cuestiona los límites del género y del sexo recurriendo a la noción de performatividad que implica el poder institu- yente de la palabra. De este modo, el habla crea la situación que nombra, sobre todo a medida que se repite como un ritual, lo que permite la naturalización de la opción sexual del sujeto y violenta la expresión de la sexualidad, especialmente la de las prácticas homosexuales y lésbicas. Estas constituirían una actuación cuasi teatral de transgresión de los límites de las normas dicotómicas que definen a los cuerpos como masculinos o femeninos, pues en ese espacio los cuerpos fluyen más allá de lo permitido por el discurso. Este marco conceptual le permite romper con el esencialismo feminista que plantea una identidad común a partir del discurso convencional basado en la elaboración cultural de las diferencias sexuales naturales y le permite construir una lógica para hablar de sujeto humano sin tener como referencia el sexo o el género. Pese a que el trabajo de Butler es de difícil comprensión, su aporte radica en la posibilidad de elaborar representaciones sociales más flexibles sobre los sexos y géneros, así como una noción de sujeto asequible a todos los seres humanos sin distinción.

El pensamiento de Butler, sin embargo, reduce lo social al lenguaje y a la deconstrucción de discursos para develar el poder. De este modo, los sujetos solo tienen capacidad de acción cuando resisten a las relaciones de poder. Se trataría de sujetos constituidos momentáneamente mientras resisten el disciplinamiento presente en los distintos espacios sociales donde probablemente son víctimas porque la autora los reconoce vulnerables. En suma, Judith Butler se apropia de las herramientas de la filosofía y del psicoanálisis y cuestiona al feminismo que enfatiza la construcción cultural de la sexualidad basada en la dicotomía masculino- femenino, imputándole que sus raíces descansan en los discursos y prácticas hegemónicos. Puede así, señalar la presencia de otras prácticas alternativas que indican que las identidades son frágiles y sus fronteras cambiantes.

El problema para las ciencias sociales con este y otros supuestos de Butler que permiten deconstruir el discurso sobre género, es que la sexualidad y el cuerpo aparecen reducidos al discurso y no a su materialidad, es decir, como anatomía, biología y funcionamiento. ${ }^{14}$

Probablemente ello se deba a la dificultad para reconocer al cuerpo como un antecedente del dis-

12. En esto coincide con la lectura que Butler hace de Adrianne Rich cuando señala el tema de la heterosexualidad compulsiva como mandato cultural obligatorio.

13. Cuestión que sería necesario debatir a la luz de La experiencia vivida, segundo tomo del Segundo Sexo, donde Beauvoir analiza las formas en que la mujer, marcada por su biología, puede trascender su condición rompiendo con las construcciones culturales que la subordinan. Para una crítica de la lectura filosófica de Butler a los textos de Beauvoir, Foucault y otros autores, ver Chambers, 2009.

14. Y no solo para las ciencias sociales, pues como lo plantea Lamas también "para el estatus del psicoanálisis y las ciencias sociales en Europa. La crítica fundamental que recibe Butler es que al reducir la diferencia sexual a una construcción de prácticas discursivas y performativas niega implícitamente su calidad estructurante (Lamas 2006, p. 101). Y posteriormente agrega "aunque son varios los elementos que afectan la aceptación de la teoría de Butler uno fundamental es el estatus del psicoanálisis entre las ciencias sociales en Europa. La utilización de la teoría psicoanalítica entre las científicas sociales francesas se extiende a las británicas, y un nutrido número de antropólogos de formación lacaniana" Lamas (2006) p. 134, cita 18. 
curso. Sin embargo, también es posible que obedezca a que su pensamiento se fundamenta en una corriente del lenguaje que considera al discurso como una realidad significativa por sí misma. Esto es importante si se considera que hay autores con posiciones distintas que plantean que el lenguaje guarda relación con el mundo externo porque representa lo real (Ricoeur, Gadamer), por su capacidad de crear mundo, (en el caso del arte) o de resolver problemas, ya que también es un medio de comunicación entre los sujetos (Habermas, Touraine e incluso Geertz). Se trata de autores que se alejan de la primera corriente justamente porque están preocupados por lo social y han dado importancia al lenguaje no solo como un mecanismo de reproducción o disciplinamiento sino también, como productor de realidades elaboradas por sujetos que en su diversidad la interpretan. Como lo plantea Reygadas (2001, p. 172) "la subestimación del contexto, del sujeto y de la historia condujo a teorías de la cultura a subrayar la homogeneidad, la permanencia y el consenso. El costo pagado por una mejor comprensión de la estructura interna de los sistemas simbólicos fue muy alto", tomando en cuenta que trabajaron en un sistema cerrado separado de la realidad social.

El enfoque de Butler, legítimo desde el punto de vista del análisis del discurso dificulta su traducción a la historia y a la realidad social. También rechaza la dialéctica entre reproducción y transformación, dos dimensiones con el mismo estatus ontológico que se entrelazan en la dinámica histórica donde los sujetos realizan un trabajo interpretativo con los símbolos y códigos que reciben. ${ }^{15}$

Una lectura del trabajo de Scott hace pensar que su postura se contrapone a la de Butler. En efecto, esta última no ofrece caminos a la constitución de un sujeto que en las disciplinas sociales se ubica en relaciones de interacción. Es en la interacción que se constituyen tanto el poder de la reproducción como las reglas discursivas y los códigos simbólicos que, a través de una conjunción de factores, dan lugar a regularidades históricas. Ello implica superar la definición de la cultura como una máquina infernal de reproducción y disciplinamiento permanentes (Geertz, 1991) pues la sociedad también es una construcción donde la interacción entre sujetos y estructuras hace posible comprender las acciones en los procesos de conservación y cambio. Ello ofrece la posibilidad de generar luchas simbólicas que cuestionen el poder en que se asientan las construcciones culturales impuestas por discursos homogeneizadores. Finalmente, es importante señalar que el desafío planteado por But- ler al discurso de género contiene ideas de gran interés que Scott reconoce al dialogar con esa propuesta. ${ }^{16}$

\section{Reflexiones finales}

Desde sus orígenes en los comienzos de la modernidad y el pensamiento ilustrado, el surgimiento de la democracia y la ciudadanía, el feminismo trató de explicar la causa de la subordinación y la exclusión de las mujeres en la vida social y política. De este modo las explicaciones que otorgaron las corrientes liberales, sufragistas o socialistas, se vincularon siempre con el pensamiento democrático creyendo que siguiendo sus presupuestos se superaría la subordinación femenina. La tradición es larga y la pregunta se basó siempre en una actitud de desconcierto e indignación que apostó al progreso como factor para transformar costumbres consideradas como producto de un atraso de la población que las superaría al comprender la justicia implícita en la igualdad de los sexos. Esta opresión dio lugar a distintas corrientes que se desarrollaron hasta los años setenta cuando después de la Segunda Guerra Mundial se produjo una ruptura en el conocimiento estatuido que no lograba dar cuenta de las experiencias individuales y colectivas del siglo XX.

Como se señaló, las mujeres no permanecieron ajenas a este contexto y se rebelaron nuevamente poniendo en duda los discursos y el orden que las relegaba al silencio y a la opresión. Por ello hay que reconocer que desde los años setenta hasta que Scott elaborara el modelo analítico de la categoría género, las nuevas feministas produjeron un enorme bagaje de conocimiento alrededor de distintas disciplinas sobre el cual Scott asienta su contribución. Recuperar a Scott apunta a valorizar la lucidez con la que esta autora trascendió el entramado de ideas que se tejieron al menos durante veinte años de discusión para presentar una respuesta de gran densidad, útil como ella misma lo señala, para comprender la condición de las mujeres tanto en la vida cotidiana como en la academia. Hay que reiterar que su aporte surge fundamentalmente por la forma en que define el problema, pues al desplazar el cuestionamiento del por qué de la exclusión de las mujeres al cómo opera este proceso, logra una salida distinta.

Su modelo adquiere sentido para comprender en su historicidad las relaciones de género y su influencia en las significaciones individuales y colectivas que se articulan desde las relaciones personales hasta los niveles institucionales. Por su consistencia interna y

15. Al decir de Geertz (1991) la contingencia, la innovación, la creatividad individual son acciones simbólicas que contribuyen a la diversidad discursiva y cultural.

16. Ver Joan Scott, 2001 y Judith Butler, 2001. 
utilidad, el modelo de Scott logra una difusión que ha tenido resultados productivos cuando se abren nuevas preguntas como en el caso del postcolonialismo o del postmodernismo pero también consecuencias inesperadas, sobre todo en lo tocante a su aplicación en las instituciones gubernamentales de las que ella, sin duda, no es responsable.

De ahí que sea importante deslindar los abusos generados por su difusión de la influencia que ha teni- do en el desarrollo de nuevos conocimientos y líneas de investigación. En efecto, desde otra perspectiva, los aportes de Scott contribuyen a la comprensión del orden y el discurso que ha subordinado a los seres humanos por su condición sexual. Su trabajo nos ha otorgado claves novedosas para releer e interpretar el complejo significado de los malestares derivados de la diferencia sexual inscrita en los cuerpos, la subjetividad y la cultura en la sociedad contemporánea.

\section{Referencias}

ABELSON, Elaine; ABRAHAM, David; MURPHY; Marjorie. Interview with Joan Scott. Radical History Review, n. 45, p. 41-95, 1989.

BEAUVOIR, Simone de. El segundo sexo. México: Siglo Veintiuno, 1989.

BERGER, Peter; LUCKMAN, Thomas. La construcción social de la realidad. Buenos Aires: Amorrortu, 2006.

BOURDIEU, Pierre. Sociología y cultura. México: Grijalbo, 1990.

BOURDIEU, Pierre; WACQUANT, Loic J.D. Respuestas por una antropología reflexiva. México: Grijalbo, 1995. BOURDIEU, Pierre. La dominación masculina. Barcelona: Anagrama, 2000.

BUTLER, Judith. Variations on sex and gender: Beauvoir, Wittig and Foucault. In: BENHABIB, S.; CORNELL, D. (eds.) Feminism as critique. Minneapolis: University of Minnesota Press, 1987.

BUTLER, Judith. Gender Trouble. Feminism and subversion of identity. Nueva York: Routledge, 1990.

BUTLER, Judith. El género en disputa. El feminismo y la subversión de la identidad. México: UNAM - PUEG, 2001.

BUTLER, Judith. Fundamentos contingentes: el feminismo y la cuestión del post-modernismo, Revista La Ventana, Vol. 2, n. 13, julio de 2001.

CHAMBERS, Samuel A. Sex and the problem of the body: reconstructing Judith Butler's Theory of Sex/ Gender. Body \& Society, vol. 13, n. 4, septiembre de 2009. DE GAULEJAC, Vincent. Lo irreductible social y lo irreductible psíquico. Perfiles Latinoamericanos, $\mathrm{n}$. 21, diciembre de 2002 (volumen dedicado al tema: Subjetividad, narración y práctica social).

DUBE, Saurabh. Sujetos subalternos: capítulos de una historia antropológica. México: El Colegio de México CEAA, 2001.

FOUCAULT, Michel. Las palabras y las cosas: una arqueología de las ciencias humanas. México: Siglo Veintiuno, 1969.

FOUCAULT, Michel. La arqueología del saber. México: Siglo Veintiuno, 1970.

FOUCAULT, Michel. Historia de la sexualidad. México: Siglo Veintiuno, 3 v, 1989.
FOUCAULT, Michel. El orden del discurso. Barcelona: Tusquets, 1999.

GEERTZ, Clifford. La interpretación de las culturas. Barcelona: Gedisa, 1991.

GIDDENS, Anthony. La constitución de la sociedad: bases para la teoría de la estructuración. Buenos Aires: Amorrortu, 1984.

GIDDENS, Anthony. The transformation of intimacy: sexuality, love and eroticism in modern societies. Great Britain: Polity Press, 1992.

GOODMAN, Kenneths. El proceso de lectura: consideraciones a través de las lenguas y del desarrollo. In: FERREIRO, Emilia; GÓMEZ PALACIOS, Margarita. Nuevas perspectivas sobre los procesos de lectura y escritura. México: Siglo XXI, 1982.

HABERMAS, J. Teoría de la acción comunicativa: complementos a estudios previos. Madrid: Cátedra, 1989.

LAMAS, Marta. Feminismo: transmisiones y retransmisiones. México: Taurus, 2006.

MONOD, Jacques. Le hasard et la nécessité. Essai sur la philosophie naturelle de la biologie moderne. Paris: Le Seuil, 1970.

NUN, José. La rebelión del coro, Nexos, n. 46, p. 19-26, octubre de 1981.

REYGADAS, Luis. Entre la homogeneidad y la fragmentación: el sujeto en los estudios contemporáneos sobre cultura. Iztapalapa, Revista de Ciencias Sociales y Humanidades, año 21, n. 50, enero - junio de 2001.

RUBIN, Gayle. El tráfico de mujeres: notas sobre la economía política del sexo. Nueva Antropología, vol. 8, n. 30, 1986. (Traducción del artículo original publicado en inglés en 1975.)

SCHÜTZ, Alfred. El mundo social y la teoría de la acción social. Estudios sobre Teoría Social. Buenos Aires: Amorrortu, 1974.

SCOTT, Joan. Finding critical History. In: James M. Banner Jr.; GILLIS, John. (eds.). Becoming Historians. Illinois: The University of Chicago Press, 2009.

SCOTT, Joan. Género e historia. México: FCE - Universidad Autónoma de la Ciudad de México, 2008.

SCOTT, Joan. Gender: A useful category of historical analysis. American Historical Review, n. 91, p. 1053-1075, 1986. 
SCOTT, Joan. Gender and the politics of history. New York: Columbia University Press, 1999.

SCOTT, Joan. Experiencia. Revista La Ventana, vol. 2, n. 13, p. 42- 73, julio de 2001.

SUÁREZ, Navaz Liliana; HERNÁNDEZ, Rosalva Aída (eds). Descolonizando el feminismo: Teorías y prácticas desde los márgenes. España: Cátedra/Instituto de la Mujer/ Universitat dè Valencia, 2008.
TOURAINe, Alain. Producción de la sociedad. México: IIS-UNAM/IFAL/Embajada de Francia, 1995.

TOURAINE, Alain. ¿Podremos vivir juntos?: iguales y diferentes. México: FCE, 1997.

TOURAINE, Alain. Le monde des femmes. France: Fayard, 2006.

YOUNG, Iris M. La justicia y la política de la diferencia. Madrid: Cátedra, 2000.

\title{
On the purpose of the gender category: reading Joan Scott
}

\begin{abstract}
Joan Scott's contribution to gender theory is, nowadays, essential. Her studies on the history of feminism and the effort to articulate the gender category, starting from a historical setting, also determined by the presence and participation of women, feed the most current debates on the relations and identities related to gender. I therefore take as a pretext, the publication, in Spanish, of her book Género y Historia (Mexico, 2008) in order to stimulate the rereading of a work whose impact on feminist politics was significant. Making a critical rereading of this model can also contribute to enrich the studies that retrieve it from a gender perspective. Despite the remarkable development of gender theory, Scott's perspective tends to be used descriptively, focusing on the analysis of problems where gender inequality is limited and obvious. So, I suggest interpellate Scott, contrasting her work context and now, in order to extend the field of analysis and the comprehension of cultural and institutional logics that influence in the experience of gender relations.
\end{abstract}

Key-words: Joan Scott, gender theory, gender relations.

\section{A propósito da categoria gênero: ler Joan Scott}

\section{Resumo}

A contribuição de Joan Scott à teoria de gênero é hoje imprescindível. Seus estudos sobre a história do feminismo e seu esforço em articular a categoria de gênero, partindo de um cenário histórico determinado também pela presença e participação das mulheres, alimentam os debates mais atuais em torno das relações e identidades vinculadas com o gênero. Por isso, tomo como pretexto a publicação em espanhol de seu livro Género e Historia (México, 2008) com o fim de estimular a releitura de uma obra cujo impacto na política feminista foi significativo. Fazer uma releitura crítica desse modelo pode também contribuir para enriquecer os estudos que o recuperam desde a perspectiva de gênero. Em que pese o notável desenvolvimento da teoria de gênero, a perspectiva de Scott tende a ser utilizada de forma descritiva, privilegiando a análise de problemas em que a desigualdade das relações de gênero se mostra limitada e evidente. Sugiro então interpelar Scott, comparando o contexto de sua obra e o de agora, com o objetivo de estender o campo de análise e a compreensão das lógicas culturais e institucionais que influem na experiência das relações de gênero.

Palavras-chave: Joan Scott, teoria de gênero, relações de gênero.

Data de recebimento do artigo: 25/9/2012

Data de aprovação do artigo: 10/11/2012 